\title{
THE BEHAVIOUR OF BLOOD VESSELS AFTER EXPERIMENTAL TRANSPLANTATION OF BONE
}

\author{
M. J. Kingma and J. F. Hampe, Amsterdam, Netherlands \\ From the Orthopaedic Section of the Surgical Department, Wilhelmina-Gasthuis \\ and the Department of Pathology, Anthonie van Leeuwenhoekhuis
}

Everybody with experience in bone transplantation agrees that autogenous grafts give the best results. In clinical practice, however, it is often difficult or impossible to get an autogenous graft. This is why bone banks exist. At the orthopaedic department of the University of Amsterdam we prefer the deep-frozen homogenous graft, but many surgeons use other types of banked bone.

The results obtained in the Netherlands with deep-frozen calf bone, supplied by the Bone Transplantation Service of the Netherlands Red Cross, were disappointing: most transplants failed.

After this experience the question arose whether the calf bone could be altered and so improved. To answer this question an animal experiment simulating a clinical operation so far as possible was needed. We therefore developed an experiment which enabled us to test the reaction to various kinds of bone grafts. Later we added injection of blood vessels, following Trueta's (1947) technique. This proved to be an important improvement and the study of the behaviour of the blood vessels after bone transplantation is now the main feature of our work.

Trueta developed the technique of demonstrating small blood vessels, and he and his colleagues have shown its value in research on the physiology and pathology of bone. Stringa (1957) drew attention to the important part played by blood vessels after bone grafting. We were fortunate enough to visit the Nuffield Orthopaedic Centre in Oxford and to be instructed by Trueta in his technique of injection of blood vessels.

It is interesting to recall that about 250 years ago students from all over the world came to Amsterdam to see the injected anatomical specimens of Frederik Ruysch (1638-1731), Professor in Anatomy at the University of Amsterdam, who had developed a method of preserving anatomical specimens. He did not reveal the exact details of his technique. We know that the method consisted in injection into the blood vessels with a syringe of a redcoloured waxy substance which later hardened. Later authors assert that he used a mixture of talc, wax and cinnabar. The specimens were preserved in alcohol with black pepper; dry specimens got a coating of oil and gum. Most of Ruysch's collection was bought by his most famous pupil Peter the Great; this collection, exhibited in the Academy of Sciences in Leningrad, is still in good condition.

By this injection method even the small vessels were filled. To quote Ruysch himself: "I filled the vessels by injecting this waxy substance in such a way that this substance reaches their very ends, thinner than down and cobweb." Ruysch called an injection of a body a success when the blood vessels of the periosteum of the small bones of the middle ear were filled. His books contain fine drawings of the blood vessels of the sternum and ribs and a meticulous drawing of the rich pattern of vessels of the periosteum of the tibia of a boy. In a letter to the Royal Society in London, of which he was a member, Ruysch reported about blood vessels in the hip joint.

\section{METHOD}

Windows 1 centimetre wide and 2 centimetres long were cut in the outer cortex of the iliac bones of rabbits, and bone grafts were inserted into these defects. Experiments were done using autogenous, homogenous and heterogenous grafts. After varying periods the 
animals were killed. One hundred millilitres of a mixture of equal amounts of a 2 per cent solution of Berlin blue and of micropaque were then injected into the abdominal aorta. The iliac bone was taken out, fixed in formalin and decalcified. Sections were made through the area of operation and were treated in two ways: 1) by the usual histological techniques, and 2) by the Spalteholz technique.

\section{RESULTS}

Normal control-Histological examination showed the usual appearances of iliac bone, with inner and outer layers of cortical bone, bone marrow and a few trabeculae of bone. Muscle was attached to the bone. The Spalteholz preparation showed the normal vascular pattern of bone and muscle (Fig. 1).

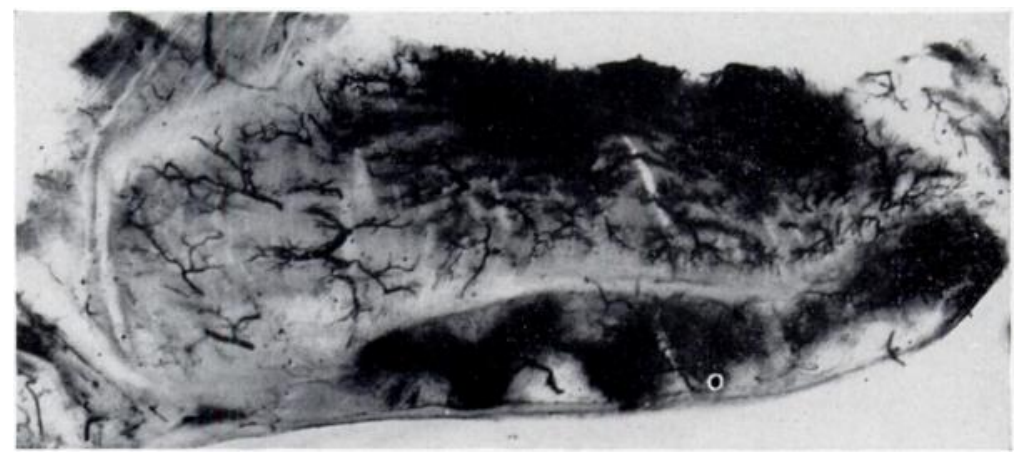

FIG. 1

Spalteholz preparation showing vascular pattern of normal ilium.

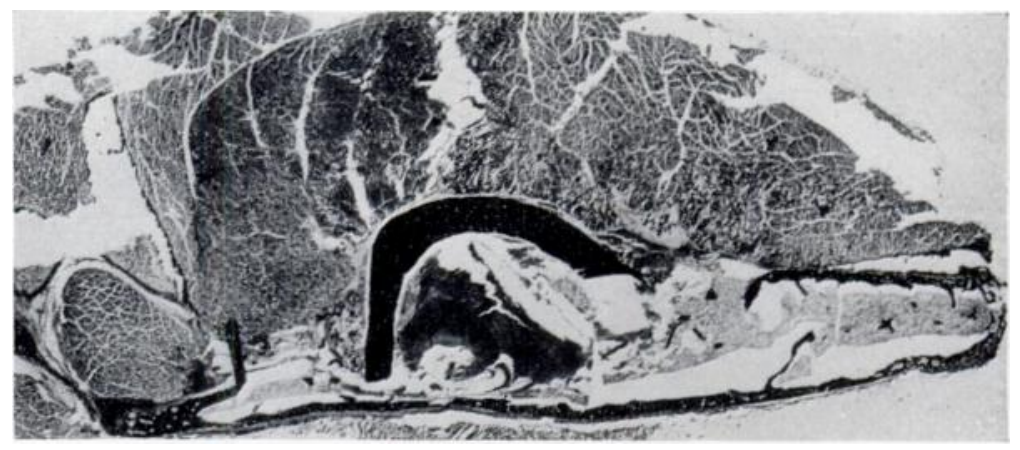

Fig. 2

Section showing autogenous cortical bone graft in place in the defect in the ilium one day after implantation.

Autogenous grafts-Pieces of bone without periosteum were taken from the shaft of the femur or of the humerus of the same animal and placed in the defect in the ilium.

One day after operation-Histological examination showed the defect in the outer cortical layer with the bone graft in the defect. The wound in the muscle and the blood around the graft were also seen (Fig. 2).

Three weeks after operation-On histological examination the graft was easily recognised. There was a great deal of new bone both subperiosteally and endosteally, filling the gap between the graft and the iliac bone (Fig. 3). Although the cells of the graft were dead blood vessels penetrated into it along the Haversian canals. New bone was being formed around these vessels and resorption of old bone was occurring (Fig. 4). 
The Spalteholz preparation showed many blood vessels surrounding the graft and a few very small ones entering it (Figs. 5 and 6).

Three months after operation-On histological examination the graft was still easily recognised. The gap was bridged by a thin bony connection and the mass of new bone had disappeared. In the graft were large holes filled with connective tissue and vessels, and there was active resorption of old bone and production of new bone around the vessels. The connecting bridge consisted of cortical bone of normal appearance (Fig. 7).

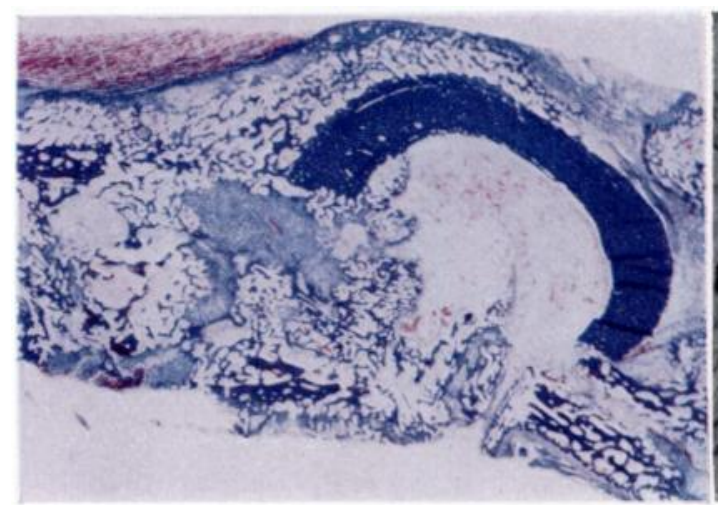

FIG. 3

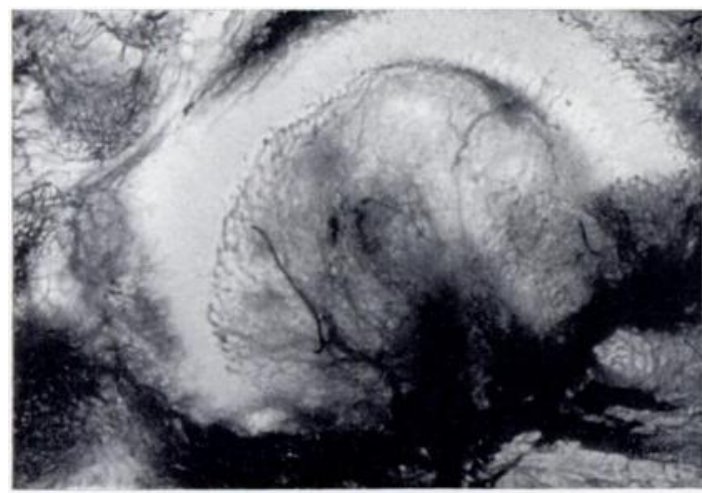

FiG. 5

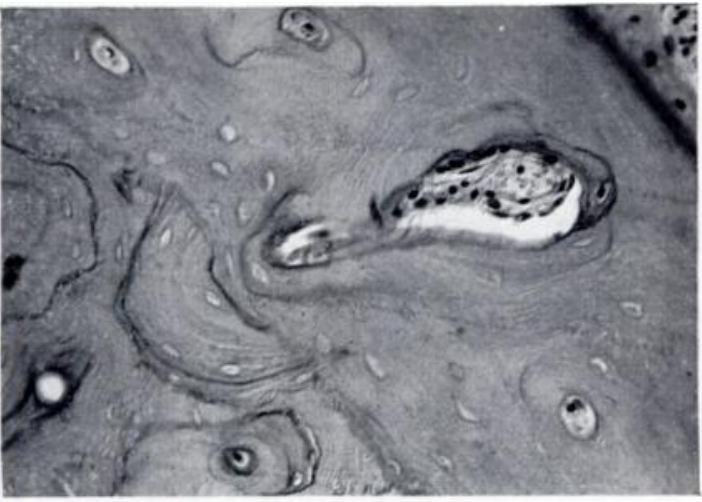

FiG. 4

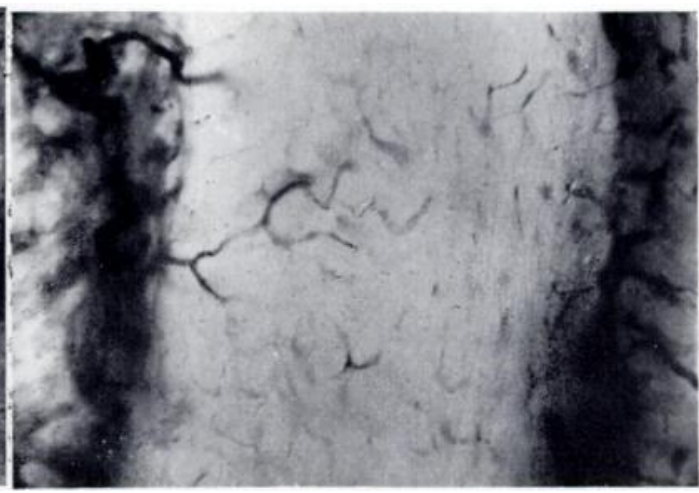

Fig. 6

Autogenous graft three weeks after implantation. Figure 3-The graft in place. Much new bone between the ilium and the graft. Figure 4-Higher magnification. The cells of the graft are dead; blood vessels penetrate the graft and there is perivascular formation of new bone. ( $\times 200$.) Figure $5-$ Spalteholz preparation, showing vessels around the graft. Figure 6-Spalteholz preparation, higher magnification, showing vessels penetrating the graft.

Six months after operation-Histological examination showed that the graft had been completely replaced by living bone, though the bone at the site of the graft was still different from the normal iliac bone (Fig. 8).

The Spalteholz preparation showed that the vascular pattern had returned to normal.

Homogenous grafts-A piece of cortical bone taken from another rabbit and preserved at a temperature of minus 40 degrees Centigrade was inserted into the defect.

Three weeks after operation-Histological examination showed that the graft was easily recognisable; new bone and cartilage were being formed in the defect (Fig. 9). The cells of the graft were dead, though one end was covered with connective tissue and cartilage from which a few blood vessels penetrated into the superficial part of the graft. There was ver: little formation of new bone (Fig. 10). 
The Spalteholz preparation showed that only a few vessels had penetrated into the graft (Fig. 11).

Ten weeks after operation-The graft showed many large holes and perivascular formation of bone. It was anchored at both ends to the ilium by new bone (Fig. 12).

The Spalteholz preparation showed many blood vessels penetrating into the graft (Fig. 13).

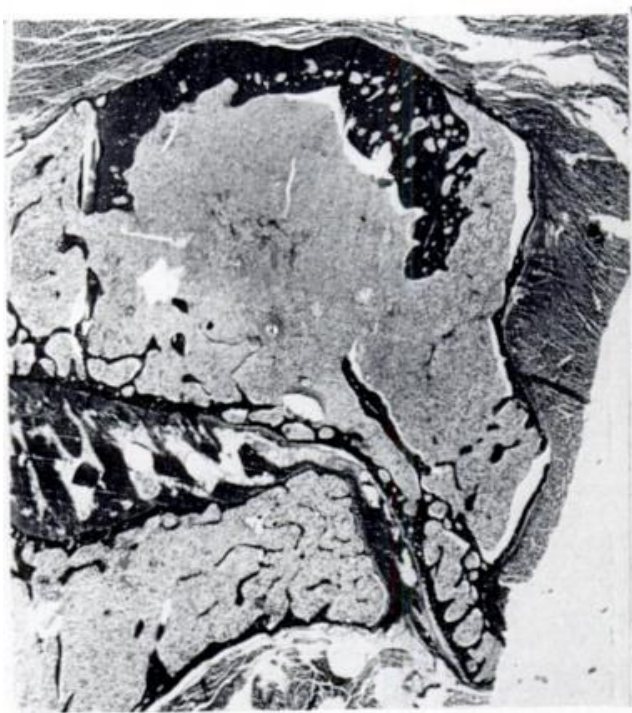

FIG. 7

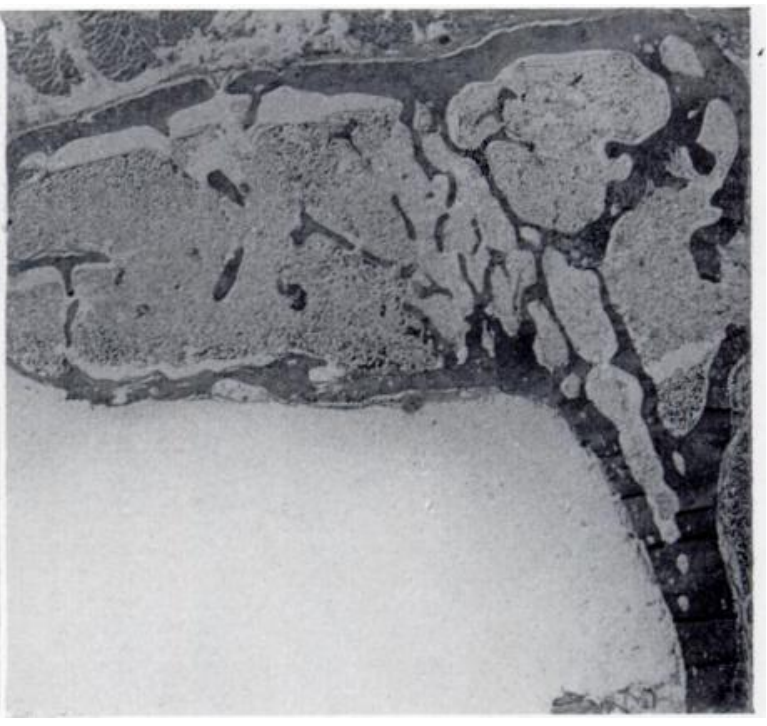

FIG. 8

Figure 7-Autogenous graft three months after implantation. There are large cavities in the graft, which is easily recognised, connected with the ilium by a thin bridge of bone. Figure 8-Autogenous graft six months after implantation. The graft has been completely incorporated.

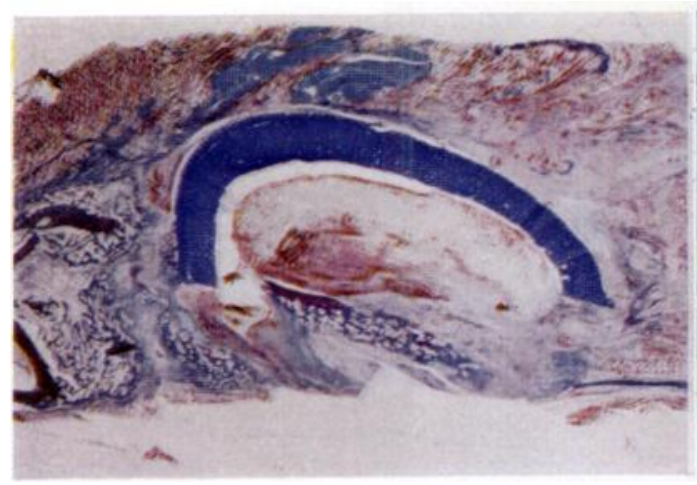

FiG. 9

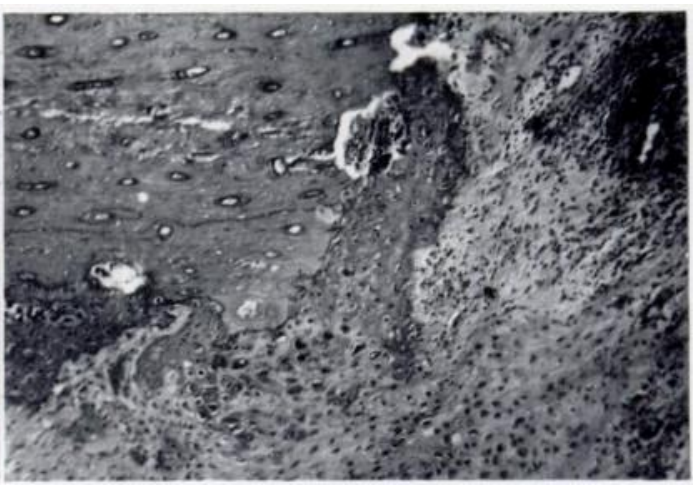

Fig. 10

Homogenous graft three weeks after implantation. Figure 9-The graft in place. New bone formation between the ilium and the graft. Figure 10-Higher magnification. The dead graft is in contact with cartilage, but there is very little production of bone. $(\times 70$.)

Six months after operation-There was a bony connection between the iliac bone and the graft, but the graft could still be recognised. Part of the graft was recognisable as the original dead bone, but on both surfaces there was a layer of new bone, blood vessels and osteoblasts (Fig. 14).

The Spalteholz preparation showed that there was only poor vascularisation of the original parts of the graft.

One year after operation the graft was completely replaced by mature bone (Fig. 15). 
Heterogenous grafts - A piece of cortical bone was taken from a calf, preserved at a temperature of minus 40 degrees Centigrade and inserted into the defect in the ilium.

Three weeks after operation-There was much new bone and cartilage in the defect. The new bone had been produced by the periosteum and endosteum of the ilium and was in contact with the graft. The graft was dead, but was being penetrated by connective tissue with cells and blood vessels. Around the vessels new bone was being formed (Fig. 16).

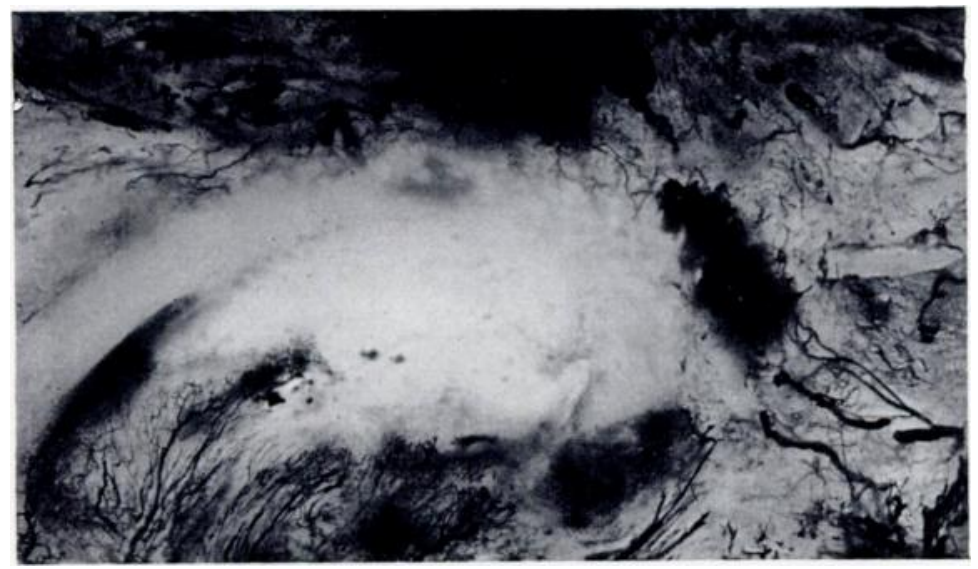

FIG. 11

Homogenous graft three weeks after implantation. Spalteholz preparation. Many vessels around the graft, but few have penetrated it.

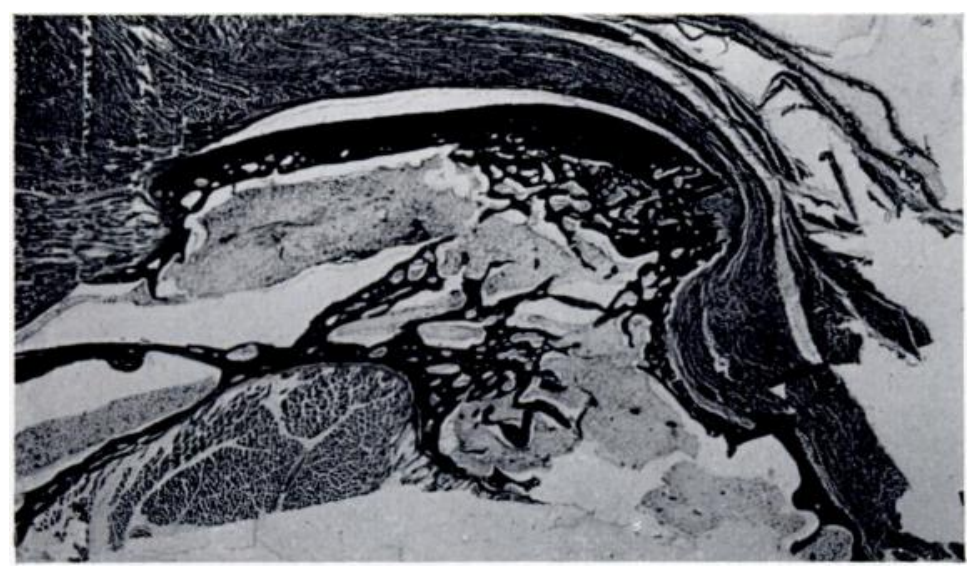

Fig. 12

Homogenous graft ten weeks after implantation. There are large cavities in the graft, which is firmly anchored at both ends to the ilium.

The Spalteholz preparation showed many blood vessels surrounding the graft and a few penetrating it (Fig. 17).

Four weeks after operation-The appearances were much the same as those at three weeks. but there was a zone of inflammatory cells around the graft (Fig. 18). This zone was made up of lymphocytes, plasma cells and eosinophils (Fig. 19).

The Spalteholz preparation showed many blood vessels penetrating the lower part of the graft by its pre-existing canals (Fig. 20).

Six months after operation-The graft was surrounded by fibrous tissue and inflammatory cells, but on one side was connected with the ilium by a thin bridge of bone (Fig. 21). The

VOL. 46 B, NO. 1, FEBRUARY 1964 
cells of the graft were dead, and it was pitted with large cavities filled with connective tissue. There was no osteoblastic activity (Fig. 22).

The Spalteholz preparation showed only a few rather large vessels in the graft (Fig. 23). Nine months after operation the graft was still dead and surrounded by a layer of fibrous tissue (Fig. 24).

\section{DISCUSSION}

The graft, whether autogenous, homogenous or heterogenous, dies. The autogenous and homogenous grafts are revascularised and replaced; the heterogenous graft remains as a dead

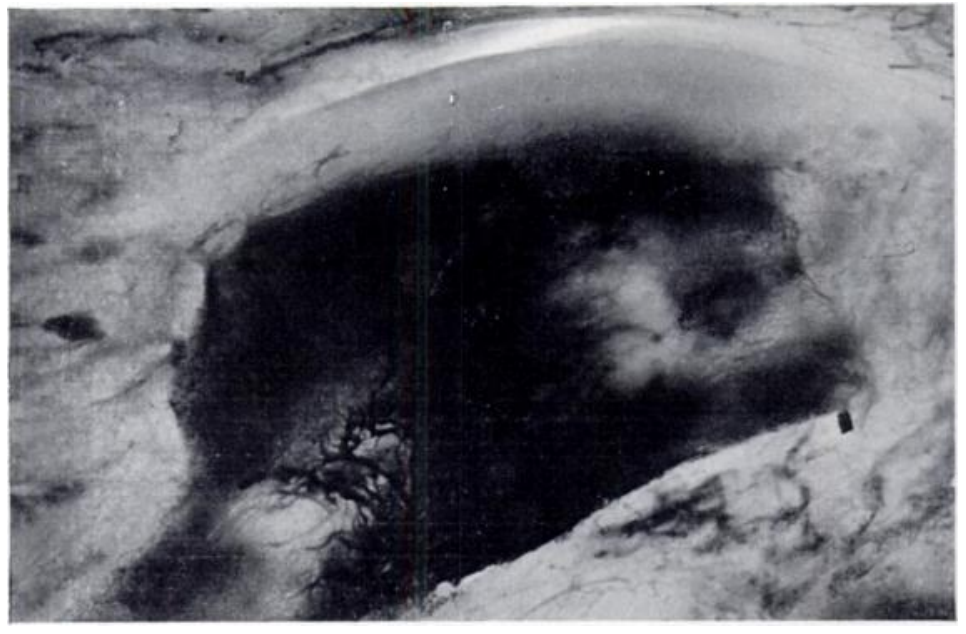

Fig. 13

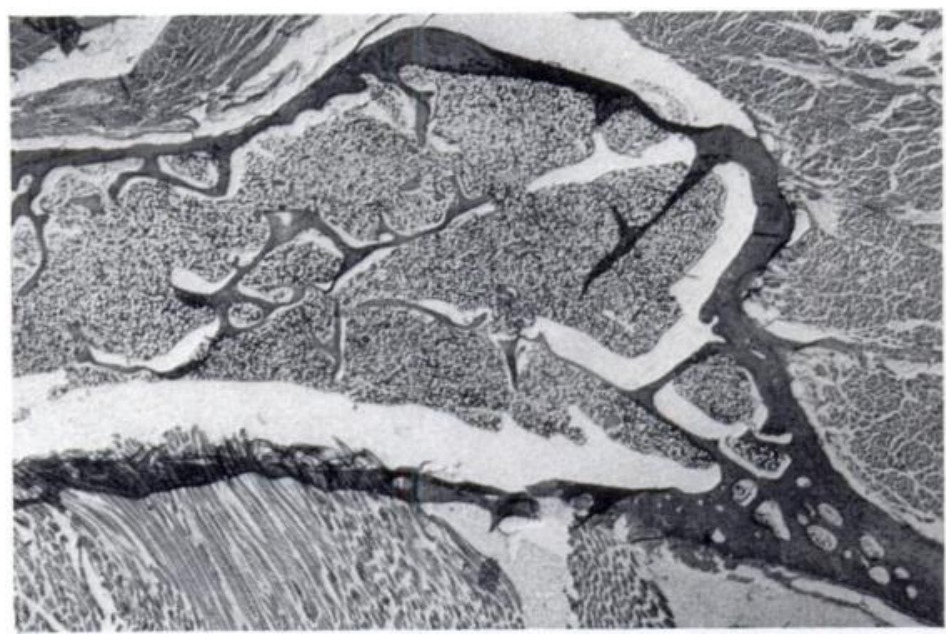

FI3. 15

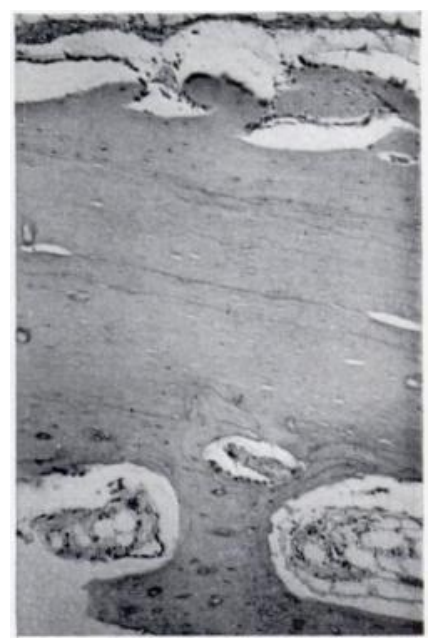

Fig. 14

Figs. 13 тo 15

Homogenous graft: process of implantation. Figure 13-Ten weeks after implantation. Spalteholz preparation. Many vessels have penetrated the graft. Figure 14-Six months after implantation. The dead graft is covered on both surfaces by new bone with vessels and osteoblasts. $(\times 60$.) Figure 15-One year after implantation. Incorporation is complete.

foreign body. While the state of the homogenous graft is finally the same as that of the autogenous one, the process of replacement is much slower in the former case. The homograft process differs in the following ways: 1) The formation of new bone is slower, 2) the new bone is slower in making contact with the graft, 3) vascular penetration is slower and less dense, and 4) the replacement of the graft is slower. There is less perivascular bone formation and more surface bone replacement. The timing of the different phases is shown in Table I. 


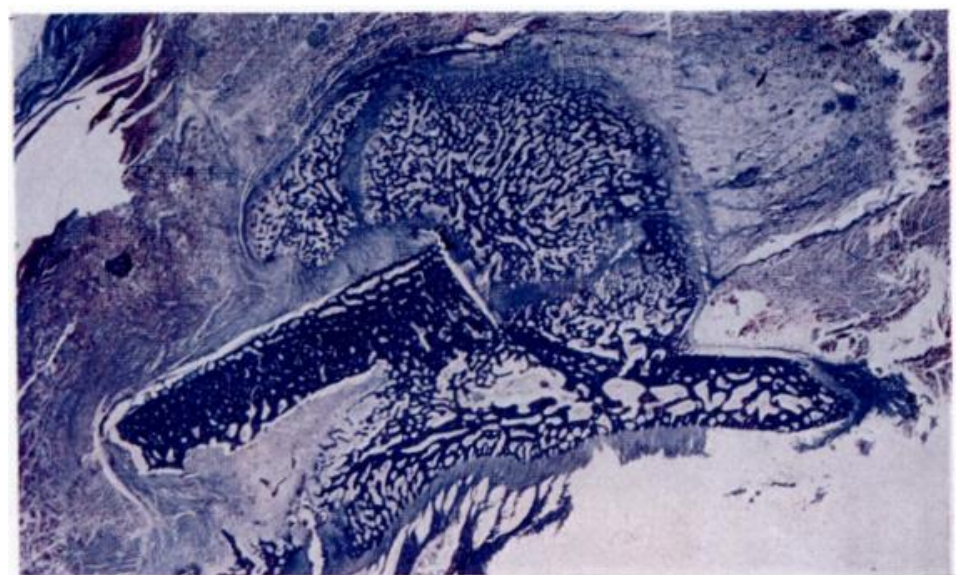

FIG. 16

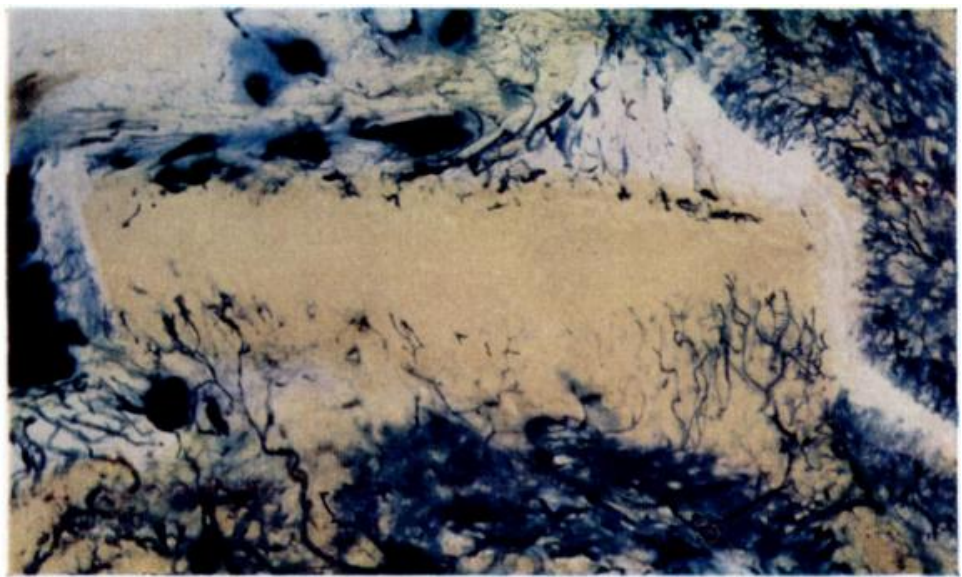

FIG. 17

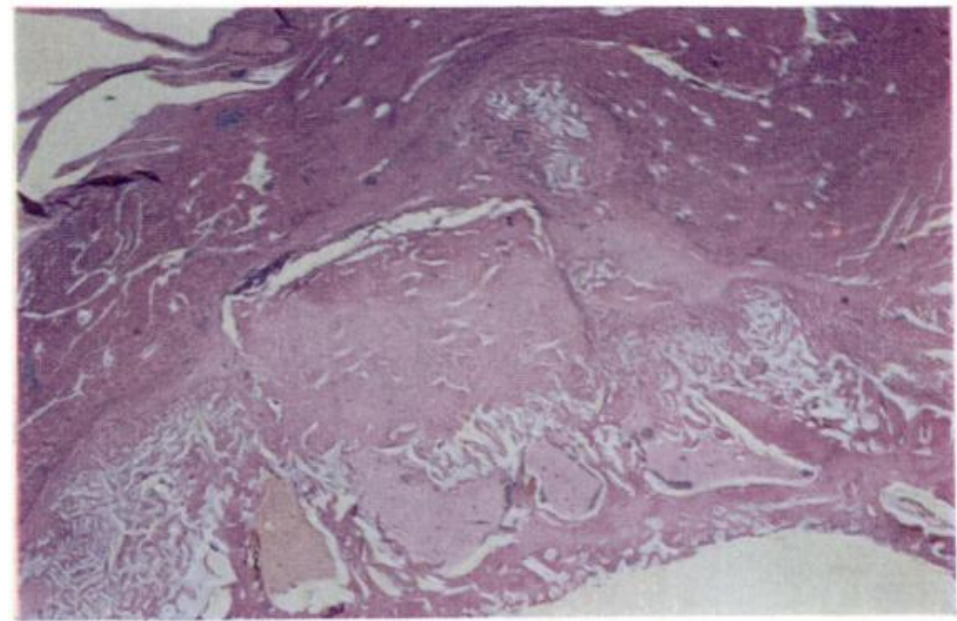

FIG. 18

Heterogenous graft, early phases. Figure 16-Three weeks. There is a wide bridge of bone between the ilium and the graft and there is new bone and cartilage in the space between them. Figure 17-Three weeks, Spalteholz preparation. Many vessels around the graft; a few penetrate the graft. Figure 18-Four weeks. Inflammatory reaction around the graft. The zone of inflammatory cells is indicated by the bluish line surrounding the graft.

VOI. 46 B, NO. 1, fEBRUARY 1964

$\mathrm{K}_{(8)}$ 
In the case of the heterograft the early phases are similar to those seen with the other grafts. About four weeks after implantation the picture changes with the appearance of an inflammatory reaction. The graft remains for long periods as a dead foreign body, though in course of time penetration of the graft by blood vessels leads to perivascular resorption and eventual complete removal of the foreign matter.

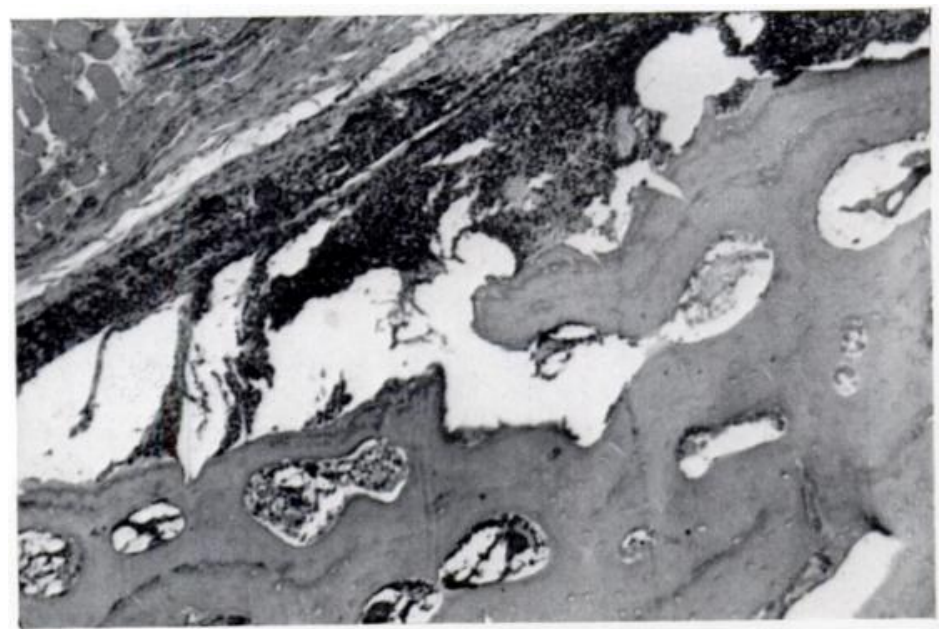

FiG. 19

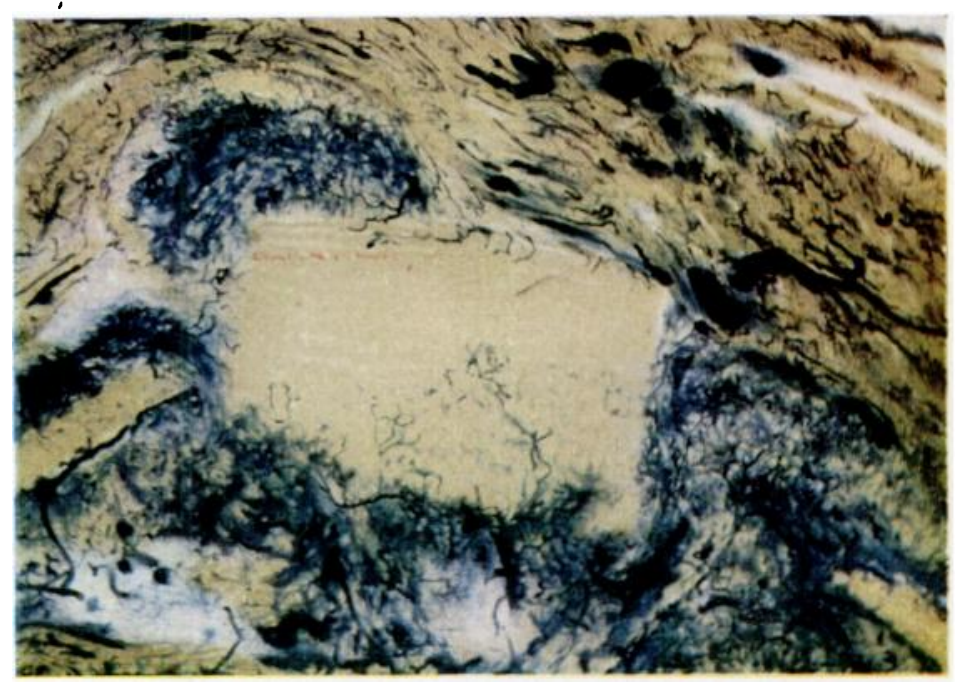

FIG. 20

Heterogenous graft. The early stage of rejection. Figure 19-Four weeks. Inflammatory cells around the dead graft. $(\times 90$.) Figure 20-Four weeks. Spalteholz preparation. Quite extensive vascular penetration in the lower part of the graft.

It is probable that this rejection is caused by an immune response. The heterograft contains antigens which, in the case of a cortical graft, only reach the circulation of the host after some time. The immune response takes the form of an imflammatory reaction. Before this the graft is accepted and reconstructive activities start. As soon as the immune response becomes active the process of acceptance stops and the connections already established are destroyed, fibrous tissue being produced instead of bone. Thus the graft is isolated and no fresh antigens come into the circulation. The reaction slows down and the dead graft remains 


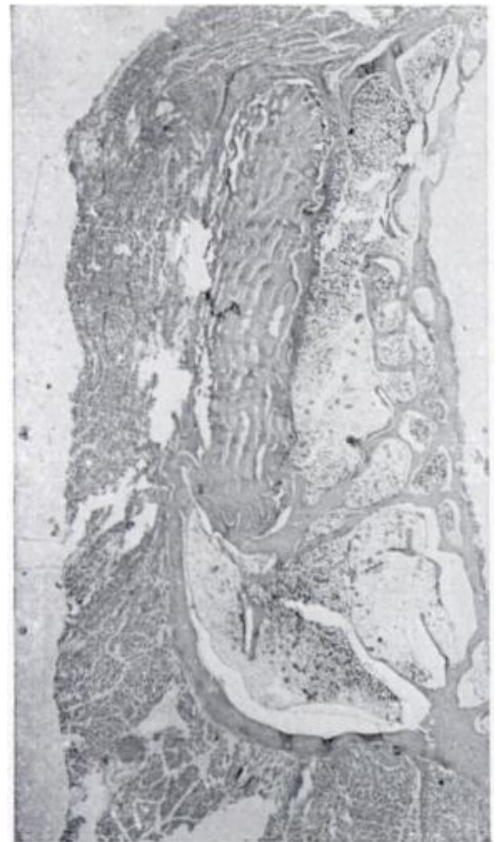

Fig. 21

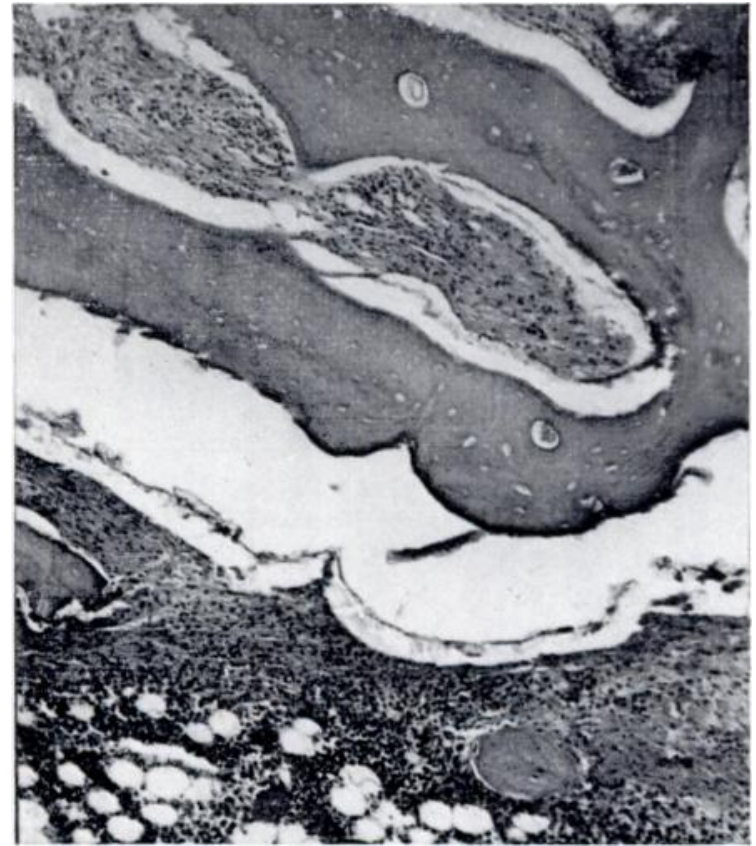

FIG. 22

Heterogenous graft. Fibrous reaction at six months. Figure 21 - The graft surrour ded by fibrous tissue and inflammatory cells. Figure 22-Higher magnification, showing fibrous reaction, chronic inflammatory cells and resorption of bone. $(\times 90$.

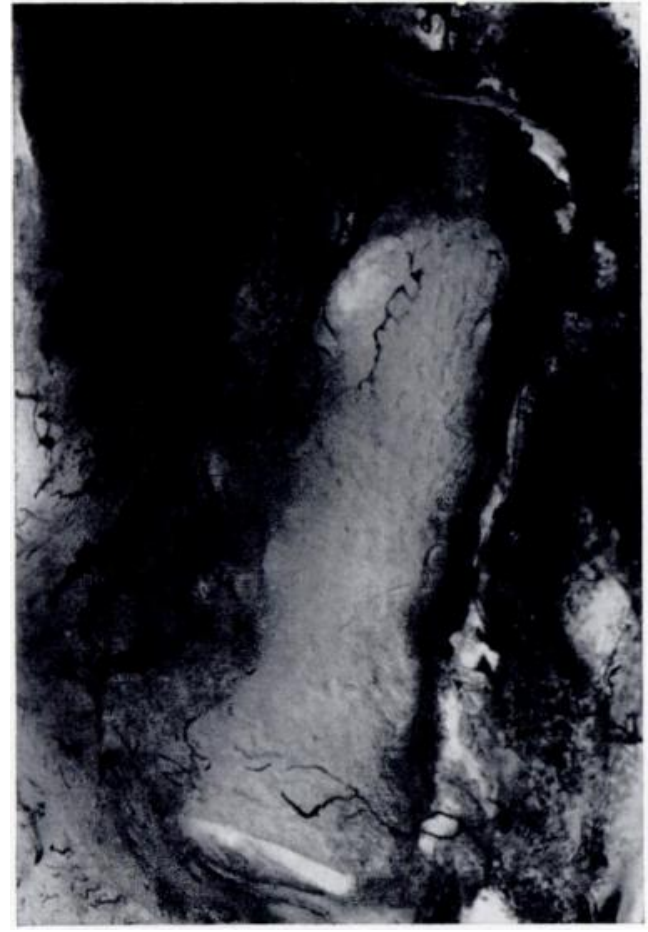

FIG. 23

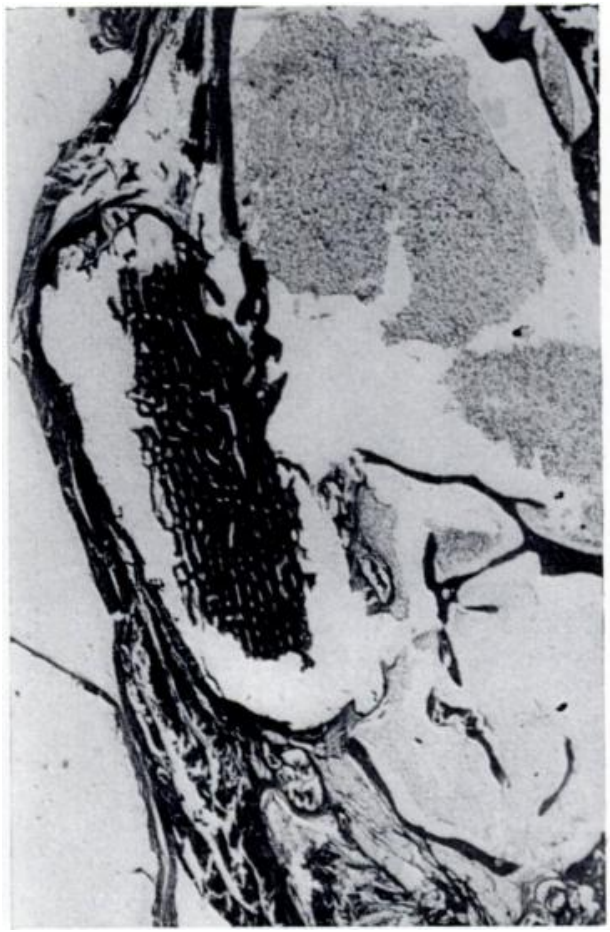

FIG. 24

Heterogenous graft: the late stages. Figure 23-Six months after implantation. Spalteholz preparation. There are a few rather large vessels in the graft. Figure 24-Nine months after implantation. The graft is enclosed in a layer of fibrous tissue.

VOL. 46 B, NO. 1, FEBRUARY 1964 
an inert foreign body. We cannot explain why sometimes the graft is slowly and completely resorbed and sometimes remains as a foreign body enveloped in fibrous tissue. Plainly, if the immune response is accepted as the cause of rejection, the problem relevant to clinical practice is that of removing the antigens from the graft without changing its other properties.

TABLE I

The Timing of the Different Phases of Incorporation of AUTOGRAFTS AND HOMOGRAFTS

\begin{tabular}{|c|c|c|}
\hline \multirow{2}{*}{ Phase of incorporation } & \multicolumn{2}{|c|}{ Time (weeks) } \\
\hline & Autograft & Homograft \\
\hline Contact of new bone with graft & 3 & 10 \\
\hline Good vascular penetration & 3 & 10 \\
\hline Incorporation complete . & 25 & 50 \\
\hline
\end{tabular}

\section{SUMMARY}

1. The behaviour of various types of cortical bone graft has been studied in rabbits by histological and injection techniques.

2. The results suggest that penetration of the graft by blood vessels plays an important part in the incorporation of autogenous and homogenous grafts.

3. Autogenous and homogenous grafts are both incorporated - the latter more slowly than the former-but heterogenous grafts are rejected. The reasons for this rejection are discussed.

We would like to express our gratitude to Professor J. Trueta for making us familiar with his technique of examination of blood vessels. We want to thank Professor A. de Froe and Dr M. A. van Dongen for their help in our investigations into Ruysch's work.

\section{REFERENCES}

Arlebout, Y. G. (1744): Werken van Frederik Ruysch. Amsterdam: Ed. Janssoons van Waesberge.

Barclay, A. E. (1951): Micro-arteriography. Oxford: Blackwell Scientific Publications.

Kingma, M. J. (1960): Results of Transplantations with Preserved Calf Bone. Archivum Chirurgicum Neerlandicum, 12, 221.

Lindeboom, G. A. (1962): Frederik Ruysch' Anatomische Preparatenverzameling te Leningrad. Nederlandsch Tijdschrift voor Geneeskunde, 106, 32.

RUYSCHII, Frederici (1723): Opera omnia anatomico-medico-chirurgica. Amstelodamum: apud JanssonioWaesbergios.

Stringa, G. (1957): Studies of the Vascularisation of Bone Grafts. Journal of Bone and Joint Surgery, 39-B, 395. Trueta, J. (1947): Studies of the Renal Circulation. Oxford: Blackwell Scientific Publications.

Trueta, J., and Harrison, M. H. M. (1953): The Normal Vascular Anatomy of the Femoral Head in Adult Man. Journal of Bone and Joint Surgery, 35-B, 442. 